\title{
Real-life use of fluticasone propionate/salmeterol in patients with chronic obstructive pulmonary disease: a French observational study
}

\author{
Nicolas Roche ${ }^{1 *}$, Céline Pribil ${ }^{2}$, Eric Van Ganse ${ }^{3}$, Philippe Serrier ${ }^{1,4}$, Bruno Housset $^{5}$, Déborah Poirier ${ }^{6}$,
} Nathalie Texier ${ }^{6}$, Stéphane Schück ${ }^{6}$ and Isabelle Boucot ${ }^{7}$

\begin{abstract}
Background: In Europe, administration of an inhaled corticosteroid (ICS) combined with a long-acting $\beta 2$ agonist is approved in chronic obstructive pulmonary disease (COPD) patients with a pre-bronchodilator $\mathrm{FEV}_{1}<60 \%$ predicted normal, a history of repeated exacerbations, and who have significant symptoms despite regular bronchodilator therapy. Minimal data are available on the use of the fluticasone propionate/salmeterol xinafoate combination (FSC) in the real-life COPD setting and prescription compliance with the licensed specifications.

Methods: A French observational study was performed to describe the COPD population prescribed with FSC, prescription modalities, and the coherence of prescription practices with the market authorized population. Data were collected for patients initiating FSC treatment $(500 \mu \mathrm{g}$ fluticasone propionate, $50 \mu \mathrm{g}$ salmeterol, dry powder inhaler) prescribed by a general practitioner (GP) or a pulmonologist, using physician and patient questionnaires.

Results: A total of 710 patients were included, 352 by GPs and 358 by pulmonologists. Mean age was over 60 years, and $70 \%$ of patients were male. More than half were retired, and overweight or obese. Approximately half were current smokers and one-third had cardiovascular comorbidities. According to both physician evaluation and GOLD 2006 classification, the majority of patients (>75\%) had moderate to very severe COPD. Strict compliance by prescribing physicians with the market-approved population for dry powder inhaler SFC in COPD was low, notably in ICS-naïve patients; all three conditions were fulfilled in less than a quarter of patients with prior ICS and less than $7 \%$ of ICS-naïve patients.

Conclusions: Prescription of dry powder inhaler SFC by GPs and pulmonologists has very low conformity with the three conditions defining the licensed COPD population. Prescription practices need to be improved and systematic FEV 1 evaluation for COPD diagnosis and treatment management should be emphasized.
\end{abstract}

Keywords: COPD, France, GOLD, Prescription, Questionnaire, Population-based, Primary care, Pulmonologist

\section{Background}

The economic and social burden of chronic obstructive pulmonary disease (COPD) is considerable, with a projection that COPD will be the third leading cause of death by 2020 [1]. Pharmacologic management for patients suffering from COPD is based on the use of bronchodilators, associated or not with a corticosteroid [2]. The therapy prescribed depends on COPD severity, prior

\footnotetext{
* Correspondence: nicolas.roche@htd.aphp.fr

${ }^{1}$ Respiratory and Intensive Care Medicine, Cochin Hospital Group, AP-HP, University Paris Descartes, HIA du Val de Grâce 4e C, Paris, France

Full list of author information is available at the end of the article
}

treatment(s), their efficacy and tolerance, and patient preference regarding inhalers. In the most recent GOLD (Global initiative on Obstructive Lung Disease) global strategy document, four patient categories are defined (A, B, C and D) based on exacerbation risk and symptoms burden [2]. Exacerbation risk is assessed according to GOLD category for forced expiratory volume in $1 \mathrm{sec}-$ ond $\left(\mathrm{FEV}_{1}\right)$ and past history of exacerbations, while symptoms burden is assessed by the modified Medical Research Council (mMRC) dyspnea grading scale and/or the COPD Assessment Test (CAT), based on the worst case scenario. For patients with $\mathrm{FEV}_{1}<50 \%$ predicted 
normal or a history of at least two exacerbations per year or one hospitalization for COPD exacerbation or both, combinations of inhaled corticosteroids (ICS) and long-acting $\beta 2$ agonists (LABA) are recommend among first-line treatments.

Administration of the ICS fluticasone propionate with the LABA salmeterol xinafoate (fluticasone /salmeterol combination, FSC) with a dry powder inhaler was approved in Europe in 2003, at a dose of $500 \mu \mathrm{g}$ fluticasone propionate with $50 \mu \mathrm{g}$ salmeterol twice daily for treatment of COPD patients with a pre-bronchodilator $\mathrm{FEV}_{1}<60 \%$ predicted normal, a history of repeated exacerbations, and who have significant symptoms despite regular bronchodilator therapy. The change of the $\mathrm{FEV}_{1}$ threshold from $<50 \%$ in the GOLD guidelines [2] to $<60 \%$ was mainly influenced by the TORCH study [3].

Coherence between published COPD guidelines and clinical prescription practices in the real-world setting has been brought into question [4-6]. Several reports highlight that a high proportion of patients who are prescribed inhaled medications, have not undergone spirometric testing to confirm diagnosis and severity [7-11]. Data on FSC use in the real-life COPD setting are scarce and co-therapies in patients prescribed with this combination as long-term treatment have not been reported.

Following a request by the French Health Authorities, a national, prospective, population-based, observational study was performed in adult COPD patients initiating treatment with fluticasone propionate/salmeterol (500/ $50 \mu \mathrm{g}$ ) administered with a dry powder inhaler, prescribed by a general practitioner (GP) or pulmonologist. The study purpose was twofold; the first step was to collect data describing patient characteristics and treatment modalities in this population, and to analyze the coherence of the prescription population with the licensed COPD population according to the Summary of Product Characteristics (SPC). In the second step, clinical outcomes after 12-months treatment with SFC in this population were evaluated. The present article reports results regarding the first of these two goals.

\section{Methods}

\section{Study design}

This was a prospective observational cohort study with 1-year follow-up in COPD patients initiating treatment with FSC delivered via a dry powder inhaler (Seretide ${ }^{\oplus}$ Diskus $\left.^{\oplus}, 500 / 50 \mu \mathrm{g}\right)$. It was performed in France between March 2008 and July 2009. Patients were included by GPs and pulmonologists who were randomly selected from a validated national database of all registered physicians (Cegedim). GPs agreeing to participate were requested to include two to four consecutive eligible patients and pulmonologists to include six to nine consecutive patients. Data were collected at inclusion and at routine follow-up visits using physician questionnaires and patient self-administered questionnaires. The study was approved by the French Advisory Committee for Data Processing in Health Research (CCTIRS) and the French Data Protection Authority (CNIL) and was conducted in accordance with the Declaration of Helsinki and local regulations (etrack number: 108314). Signed informed consent was obtained from all patients.

\section{Patient population}

To be eligible, patients had to be clinically diagnosed with COPD, initiating FSC therapy prescribed by a GP or a pulmonologist at inclusion, aged 40 years or older, and be current or former smokers with a history of at least 15 pack-years. Patients were ineligible if they had asthma, tuberculosis, cystic fibrosis, any other pulmonary condition, or cancer at inclusion, had received anticancer treatment during the previous 3 years, or were participating in another clinical or epidemiologic study.

\section{Questionnaires and data collection}

Patient data reported by the physician at inclusion included sociodemographics, disease history (including smoking) and the following cardiovascular comorbidities: (i) cardiovascular diseases including heart failure, coronary heart disease, peripheral vascular disease, and other cardiovascular diseases (e.g., arrhythmias, valve diseases) but excluding metabolic risk factors (diabetes, hypercholesterolemia); (ii) hypertension. In addition, spirometric measurements, blood gas levels and weight were recorded at inclusion and, when performed, at each follow-up visit. Cough, expectoration, and wheezing during the 3 months prior to inclusion or any follow-up visits were reported, as well as dyspnea (modified MRC scale). Other variables included exacerbations and their management during the 12 months prior to inclusion or between visits, along with COPD treatments (bronchodilators, corticosteroids, antibiotics, physician and hospital visits, vaccinations, non-drug therapies) over the same period. On the day of enrollment, a patient selfadministered questionnaire was used to evaluate dyspnea (Borg scale [12]) and quality of life (QoL; Clinical COPD Questionnaire, CCQ) [13], on the basis of the week prior to the visit. Demographics and practice data were collected for physicians.

\section{Evaluations and statistical analyses}

A minimum of 267 patients per group (i.e., included by GPs or by pulmonologists) was required to estimate the frequency of any event occurring in about $50 \%$ of patients with a $5 \%$ type I error and a precision (i.e. maximum variation allowed around the estimate) of 6\%. COPD severity was classified according to GOLD 2006 [14], taking into account $\mathrm{FEV}_{1}$, and to GOLD 2011 (which was not available 
at the time the study was performed) [15] taking into account $\mathrm{FEV}_{1}$, dyspnea MRC score, and history of exacerbations. Prescriptions were considered compliant with the SPC when the following three conditions were fulfilled at inclusion: 1) $\mathrm{FEV}_{1}<60 \%$ predicted; 2) a history of repeated exacerbations (at least two over the last year, defined as an emergency department visit, hospitalization, or a course of oral corticosteroids or antibiotics for respiratory problems); 3) significant symptoms despite regular bronchodilator therapy alone (with a long-acting $\beta 2$-mimetic or longacting anticholinergic agent).

Analyses were performed according to physician specialty using descriptive statistics. Data were further analyzed in terms of prior ICS intake versus ICS-naïve. A conservative approach was used such that missing data for $\mathrm{FEV}_{1}$, exacerbations and long-acting bronchodilators criteria were considered as non-fulfillment of the SPC criteria. A first sensitivity analysis was performed excluding patients without $\mathrm{FEV}_{1}$ data given the high proportion of patients for whom this examination was not performed, and a second analysis excluded prior repeated exacerbations, given that this is a composite criterion and considered to be less reliable than other criteria.

Agreement between investigator-assessed and GOLD 2006 classifications was evaluated with a weighted Kappa test. Comparisons within GP or pulmonologist populations (ICS-naïve versus ICS-treated patients; including versus non-including physicians) were performed using student's t-tests and variance analysis (after a Levene test for homogeneity of variance) for quantitative data. Normality was confirmed with histograms and Shapiro-Wilk tests. Satterthwaite's approximation or Kruskal-Wallis tests were used in cases of unequal variance. Nonparametric tests were applied in the absence of normal distribution. A Wilcoxon test was used for paired series. $\mathrm{Chi}^{2}$ or Fisher exact tests were used to compare qualitative data. Significance comparisons of GP versus pulmonologist patient populations were not performed given that these populations were recruited in different settings during partially different time periods. A significance threshold of 0.05 was used and analyses were performed with SAS (v.9.1, SAS Institute, North Carolina USA).

\section{Results}

Overall $6.3 \%$ of the GPs (419 of 6620 ) and $8.7 \%$ of pulmonologists (177 of 2030) who were contacted agreed to participate (Figure 1). Of them, 162 GPs and 88 pulmonologists included at least one patient, with GPs including a median of two patients while pulmonologists included a median of 4.5 patients. A comparison of demographic and practice characteristics of physicians including patients with those of the national population of physicians and also with physicians who agreed to participate but did not include patients are provided in Additional file 1.

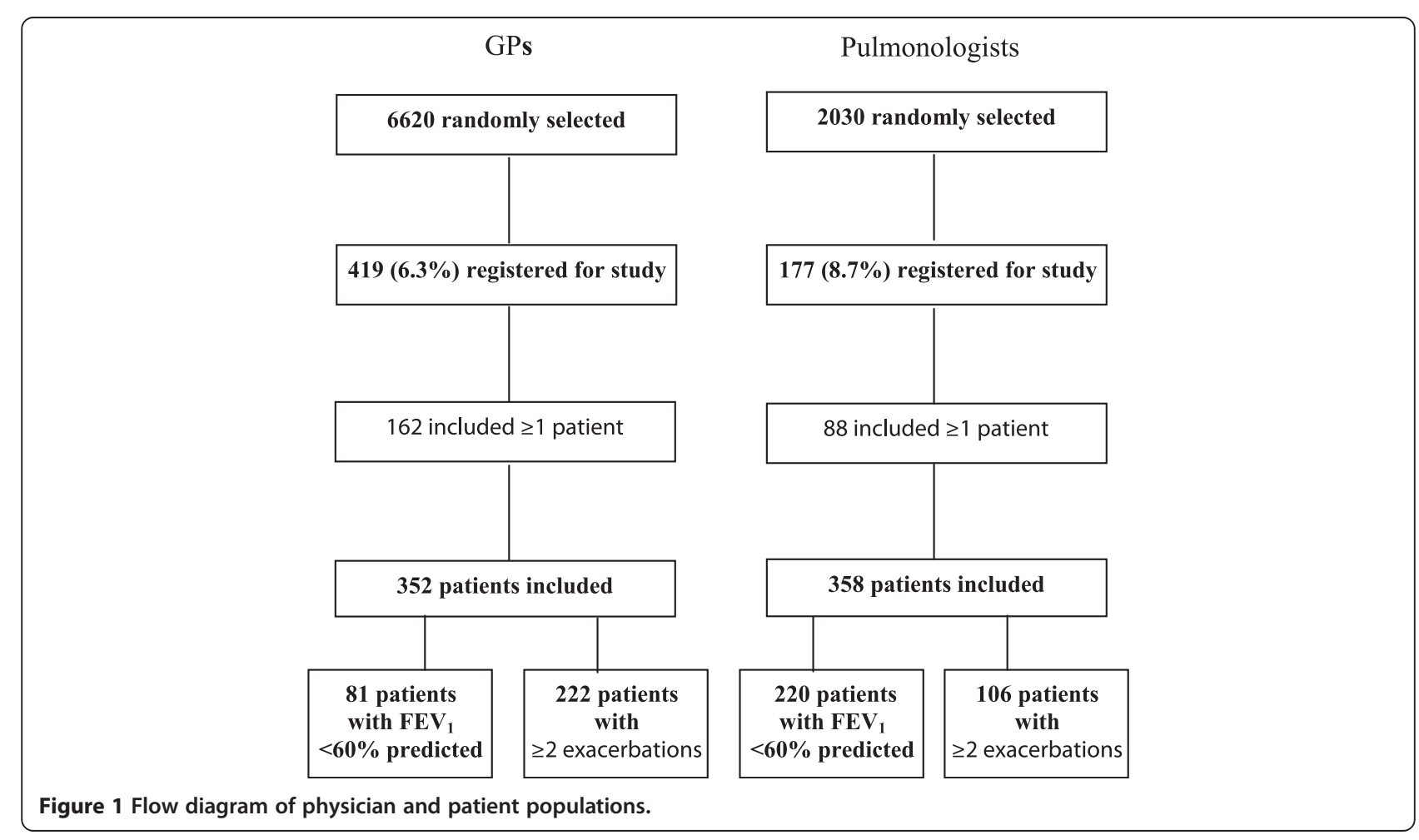




\section{Patient population}

A total of 710 patients initiating an SFC prescription were included, 352 by GPs and 358 by pulmonologists (Figure 1). Sociodemographic and clinical characteristics are presented in Table 1. Mean patient age was over 60 years and more than half of the included patients were retired (61\%) and overweight or obese (57\%). Almost half the patients were current smokers and cardiovascular comorbidities were reported in approximately one-third of the population. Some differences in characteristics were apparent between the GP and pulmonologist populations, with the latter having a higher proportion of patients who were retired, male, had hypertension or coronary heart disease, while fewer pulmonologist patients were current smokers. See Additional file 2 for a description of differences in patient characteristics between patients participating versus those who did not.

\section{COPD profile and therapeutic management}

At inclusion, the majority of patients had moderate to very severe COPD according to both the physician's judgment and the GOLD-defined severity of airflow obstruction [14] (Table 1). A higher proportion of patients had very severe disease according to the GOLD criteria versus investigator judgment, which was confirmed by Kappa evaluations showing that agreement between the physician and the GOLD evaluations was poor for GPs $($ Kappa $=0.25)$ and moderate for pulmonologists $($ Kappa $=$ 0.52). According to GOLD 2006 classification, pulmonologists included a higher proportion of patients with severe to very severe disease relative to GPs. FEV 1 data were available in 335 patients included by pulmonologists (94\%), but only 153 of the 352 patients included by GPs (43\%, including 8 patients with an aberrant result considered missing in the analysis). Pulmonologist patients had a poorer mean $\mathrm{FEV}_{1} \%$ predicted and worse dyspnea than patients in the GP group. See Additional file 2 for a description of differences in baseline characteristics in GP patients with $\mathrm{FEV}_{1}$ available versus those without and for a comparison of investigator-assessed COPD severity versus GOLD 2006 in patients with $\mathrm{FEV}_{1}$ data.

Chronic symptoms were common in both groups, with over $80 \%$ having chronic cough, and approximately twothirds of patients had both daily expectorations and cough (Table 1). QoL outcomes were mid-range and similar in the two groups, although symptom scores were poorer in the GP group. A history of repeated exacerbations was reported in $63 \%$ of GP patients and $30 \%$ of pulmonologist patients. Nonetheless, incidence of emergency department visits and hospitalizations was low overall with in most cases no more than one visit over 12 months, but were more common in the pulmonologist group than the GP group (Table 2). Patients in the GP group were more likely to be prescribed antibiotics and corticosteroids. Pneumococcal vaccinations had been administered in less than half the population and along with flu vaccines, were more common among GP patients than pulmonologist patients.

Prior COPD medication intake was reported in $76 \%$ of GP patients and $67 \%$ of pulmonologist patients. Coadministration of an ICS and a short-acting or longacting bronchodilator was the most common treatment, reported in approximately half these patients (144 GP, 54\%; 115 pulmonologist, 48\%). The use of short-acting and/or long-acting bronchodilators (mostly anticholinergics) without ICS was reported in 35\% of GP patients and $48 \%$ of pulmonologist patients (Table 2). Approximately one-third of both patient populations had received LABA with ICS.

Among the 710 patients included, a comparison of ICS-naive patients versus those with prior ICS showed that for both GP and pulmonologist patients the ICSnaïve patient population was older $(\mathrm{p}<0.01)$, had more severe COPD (investigator-assessed; $\mathrm{p} \leq 0.0004$ ), had been diagnosed with COPD for longer $(\mathrm{p}<0.0001)$, had worse dyspnea (MRC and Borg; $\mathrm{p} \leq 0.03$ ) and total QoL scores $(\mathrm{p}<0.01)$, were less likely to have been vaccinated $(\mathrm{p}<0.001)$, have visited a specialist $(\mathrm{p}<0.001)$, have received oral corticosteroid $(\mathrm{p}<0.0001)$ or antibiotics $(\mathrm{p}<$ 0.01 ). In addition, GP patients with prior ICS were less likely to be current smokers $(p=0.01)$, more likely to have $\mathrm{FEV}_{1}$ data available $(\mathrm{p}<0.0001$, although there was no difference in $\mathrm{FEV}_{1}$ values). Pulmonologist patients with prior ICS were more likely to be female $(\mathrm{p}<0.01)$, have lower percent predicated $\mathrm{FEV}_{1}(\mathrm{p}<0.01)$ and have consulted a GP $(p<0.01)$. See Additional file 3 for reasons for FSC prescription and further details of COPD therapies.

\section{Modalities of SFC prescription and compliance with recommendations}

The most common Seretide ${ }^{\bullet}$ Diskus $^{\bullet}$ dose prescribed was one inhalation of $500 \mu \mathrm{g}$ fluticasone propionate/ $50 \mu \mathrm{g}$ salmeterol twice daily (72\% of GP-included patients, $83 \%$ of pulmonologist patients). A dose of two inhalations twice daily was prescribed in $23 \%$ of GP patients and $12 \%$ of pulmonologist patients.

FSC use in COPD patients in the real-life context is summarized in Table 3 in terms of compliance with the SPC, and according to prior corticosteroid intake in all patients irrespective of whether $\mathrm{FEV}_{1}$ data were available. Among patients having received prior ICS, compliance with at least one of the three marketing authorization conditions for prescription was reported in over $90 \%$ of patients for both GPs and pulmonologists, however compliance with all three decreased to $16 \%$ of GP patients and $26 \%$ of pulmonologist patients. In ICS-naïve patients, these proportions decreased to $73 \%$ (GP) and $80 \%$ (pulmonologist) of patients complying with at least 
Table 1 Main sociodemographic characteristics at inclusion and clinical profile of COPD patients prescribed with FSC

\begin{tabular}{|c|c|c|c|c|}
\hline & GPs & $\begin{array}{c}\text { N patients } \\
(\mathrm{n}=352)\end{array}$ & Pulmonologists & $\begin{array}{c}\text { N patients } \\
(\mathrm{n}=358)\end{array}$ \\
\hline Age in years, mean (SD) & $61.6(11.4)$ & 352 & $65.3(11.5)$ & 358 \\
\hline Male, N (\%) & $227(64.5 \%)$ & 352 & $269(75.1 \%)$ & 358 \\
\hline Professional status, N (\%) & & 352 & & 357 \\
\hline Working & $122(34.7 \%)$ & & $57(16.0 \%)$ & \\
\hline Retired & $186(52.8 \%)$ & & $246(68.9 \%)$ & \\
\hline Other & $44(12.5 \%)$ & & $54(15.1 \%)$ & \\
\hline BMI $\left(\mathrm{kg} / \mathrm{m}^{2}\right), \mathrm{N}(\%)$ & & 349 & & 358 \\
\hline Underweight $(<18)$ & $10(2.9 \%)$ & & $25(7.0 \%)$ & \\
\hline Normal (18-25) & $131(37.5 \%)$ & & $138(38.5 \%)$ & \\
\hline Overweight (25-30) & $133(38.1 \%)$ & & $121(33.8 \%)$ & \\
\hline Obese $(\geq 30)$ & $75(21.5 \%)$ & & $74(20.7 \%)$ & \\
\hline Current smoker, $\mathrm{N}(\%)$ & $195(55.4 \%)$ & 352 & $127(35.6 \%)$ & 357 \\
\hline Pulmonary hypertension, $\mathrm{N}(\%)$ & $12(3.5 \%)$ & 343 & $32(9.2 \%)$ & 348 \\
\hline$\geq 1$ cardiovascular comorbidity, $\mathrm{N}(\%)$ & $116(33.0 \%)$ & 352 & $138(38.5 \%)$ & 358 \\
\hline Heart failure & $44(12.5 \%)$ & & $43(12.0 \%)$ & \\
\hline Coronary heart disease & $35(9.9 \%)$ & & $62(17.3 \%)$ & \\
\hline Peripheral artery disease & $48(13.6 \%)$ & & $45(12.6 \%)$ & \\
\hline Other $^{1}$ & $35(9.9 \%)$ & & $55(15.4 \%)$ & \\
\hline COPD severity (investigator), $\mathrm{N}(\%)$ & & 352 & & 358 \\
\hline Mild & 49 (13.9\%) & & $14(3.9 \%)$ & \\
\hline Moderate & $197(56.0 \%)$ & & $151(42.2 \%)$ & \\
\hline Severe & $100(28.4 \%)$ & & $152(42.4 \%)$ & \\
\hline Very severe & $6(1.7 \%)$ & & $41(11.5 \%)$ & \\
\hline COPD severity (GOLD 2006), N (\%) & & 137 & & 323 \\
\hline Grade 1 (mild) & $31(22.6 \%)$ & & $16(5.0 \%)$ & \\
\hline Grade 2 (moderate) & $62(45.3 \%)$ & & $183(56.6 \%)$ & \\
\hline Grade 3 (severe) & $13(9.5 \%)$ & & $38(11.8 \%)$ & \\
\hline Grade 4 (very severe) & $31(22.6 \%)$ & & $86(26.6 \%)$ & \\
\hline COPD severity (GOLD 2011), N (\%) & & 136 & & 319 \\
\hline Group A: Low risk, less symptoms & $20(14.7 \%)$ & & $71(22.3 \%)$ & \\
\hline Group B: Low risk, more symptoms & $15(11.0 \%)$ & & $72(22.6 \%)$ & \\
\hline Group C: High risk, less symptoms & $45(33.1 \%)$ & & $52(16.3 \%)$ & \\
\hline Group D: High risk, more symptoms & $56(41.2 \%)$ & & $124(38.9 \%)$ & \\
\hline Median time in years since diagnosis (range) & $5.0(0-40)$ & 347 & $4.0(0-30)$ & 352 \\
\hline \multicolumn{5}{|l|}{$\mathrm{FEV}_{1}$, mean $(\mathrm{SD})^{3}$} \\
\hline$\%$ predicted & $60.5(22.8)$ & 145 & $53.6(16.7)$ & 334 \\
\hline \multicolumn{5}{|l|}{ Arterial blood gas (mmHg), mean (SD) } \\
\hline $\mathrm{PaO}_{2}$ & $72.4(12.8)$ & 79 & $70.0(11.7)$ & 221 \\
\hline $\mathrm{PaCO}_{2}$ & $42.1(6.2)$ & 66 & $41.2(6.0)$ & 218 \\
\hline Dyspnea (MRC grade), N (\%) & & 349 & & 353 \\
\hline 1 (strenuous exercise) & $58(16.6 \%)$ & & $24(6.8 \%)$ & \\
\hline 2 (walking upstairs or uphill) & $146(41.8 \%)$ & & $114(32.3 \%)$ & \\
\hline 3 (walking on the flat) & $96(27.5 \%)$ & & $103(29.2 \%)$ & \\
\hline
\end{tabular}


Table 1 Main sociodemographic characteristics at inclusion and clinical profile of COPD patients prescribed with FSC (Continued)

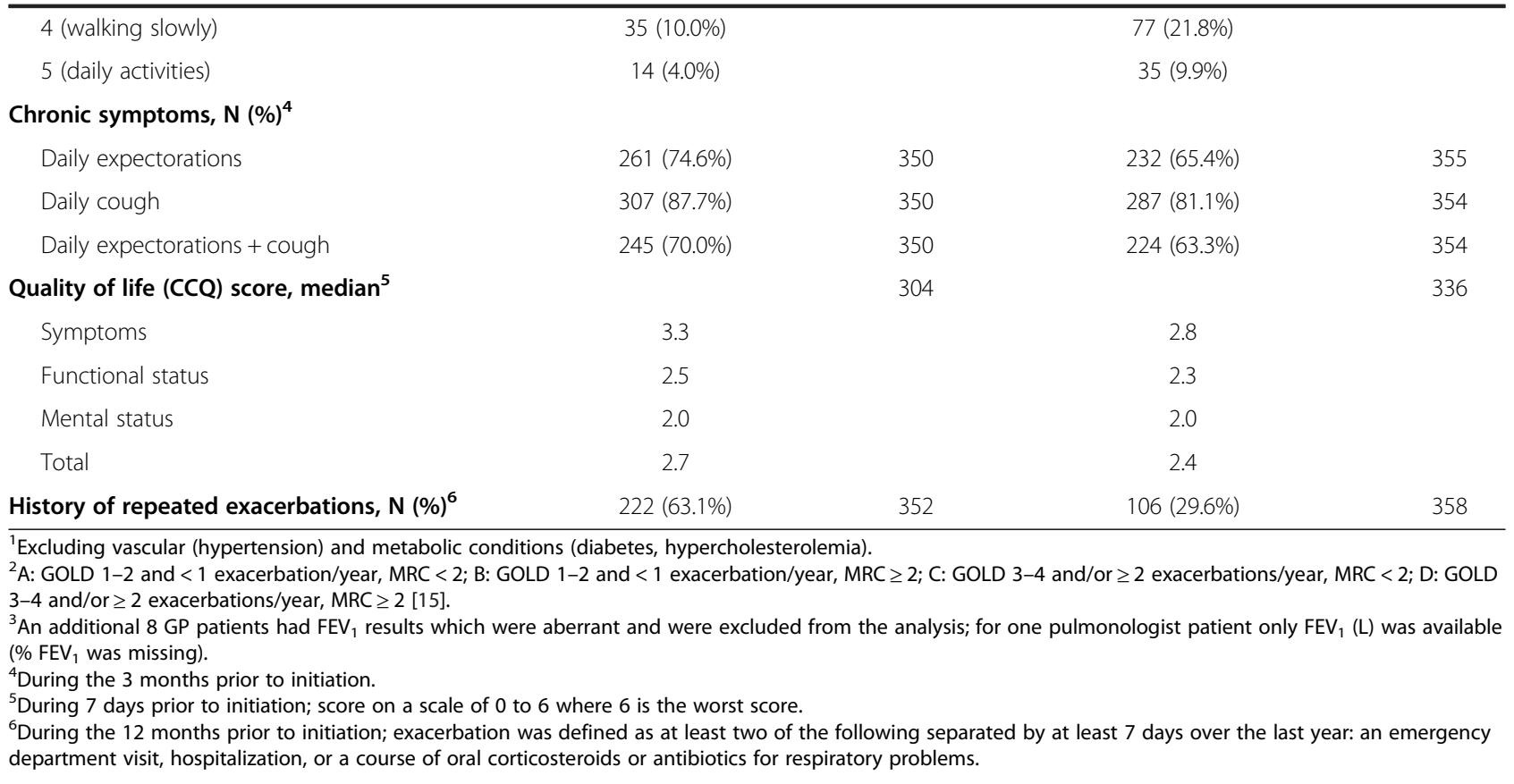

one condition, and less than $7 \%$ of patients complying with all three conditions. Compliance with the $\mathrm{FEV}_{1}<$ $60 \%$ predicted normal criteria, was considerably lower in the GP group than the pulmonologist group. Conversely, patients included by pulmonologists were less likely to have fulfilled the requirement of repeated exacerbations.

\section{Discussion}

Knowledge of real-life use of ICS/LABA combinations in the COPD setting allows for evaluation of the conformity of current prescription practices with the licensed COPD population. This can in turn be used to encourage appropriate changes in current practices to improve standards of patient care. Limited data on the use of FSC in the real-life setting have been published since the addition of COPD to the original marketing authorization for this combination based on three double-blind randomized placebo-controlled studies [16-18].

From the data obtained in this observational study of a COPD population initiating treatment with FSC administered via a dry powder inhaler, the very low rates of strict compliance with the three SPC criteria for prescription, notably in ICS-naïve patients, clearly reveal that prescribing French physicians do not adequately respect the licensing conditions. Less than a quarter of the patients with prior ICS and less than 7\% of ICS-naïve patients fulfilled all three conditions. Furthermore, a small proportion of patients did not fulfill any of the conditions. When considering both two or three of the conditions, conformance improves slightly, but is still low, being reported in approximately two-thirds of patients with prior ICS, and one-third of ICS-naïve patients.

While conformance was higher for pulmonologists than GPs in terms of the number of conditions respected and for the $\mathrm{FEV}_{1}$ and previous bronchodilator criteria, overall rates were low for both medical specialties. In the case of GPs, the discrepancy between the licensed and real-life COPD populations is due at least in part to the high rate of missing spirometry measurements, with $\mathrm{FEV}_{1}$ data available for less than half of these patients. This is coherent with several studies worldwide reporting that only around a third to a half of patients undergo spirometry testing for newly diagnosed COPD or subsequently during follow-up $[7,10,11,19,20]$. The large proportion of missing data for $\mathrm{FEV}_{1}$ among GP patients limits the assessment of concordance between prescription practices and marketing authorizations and guidelines. The conservative approach used with missing data (i.e., absence of $\mathrm{FEV}_{1}$ considered nonrespect) may have artificially lowered the rate of conformance in the GP group. Supporting this, a sensitivity analysis including only patients for whom $\mathrm{FEV}_{1}$ measures were available gave similar conformance rates between GPs and pulmonologists for this criterion (Additional file 4). Of note, the profile of patients without $\mathrm{FEV}_{1}$ measures showed them to be generally healthier than those with measures (younger, less severe 
Table 2 Therapeutic management of COPD prior to initiating fluticasone/salmeterol

\begin{tabular}{|c|c|c|c|c|}
\hline & GPs & N patients $(n=352)$ & Pulmonologists & $N$ patients $(n=358)$ \\
\hline \multicolumn{5}{|l|}{ General care, $\mathrm{N}(\%)^{1}$} \\
\hline Consultation with GP & $320(91.4 \%)$ & 350 & $251(73.6 \%)$ & 341 \\
\hline Consultation with specialist & $173(49.6 \%)$ & 349 & $215(60.6 \%)$ & 355 \\
\hline Emergency visits & $31(8.9 \%)$ & 348 & $53(14.9 \%)$ & 356 \\
\hline Hospitalizations & $38(10.9 \%)$ & 350 & $71(19.8 \%)$ & 358 \\
\hline Oral corticosteroids & $220(63.0 \%)$ & 349 & $120(33.7 \%)$ & 356 \\
\hline Antibiotics & $289(83.5 \%)$ & 346 & $194(54.6 \%)$ & 355 \\
\hline \multicolumn{5}{|l|}{ Vaccination, $\mathrm{N}(\%)$} \\
\hline $\mathrm{Flu}^{1}$ & $264(75.4 \%)$ & 350 & $214(60.1 \%)$ & 355 \\
\hline Pneumococcus (within 5 years) & $168(48.1 \%)$ & 349 & $106(30.1 \%)$ & 352 \\
\hline Prior medication, $\mathrm{N}(\%)$ & & $268^{2}$ & & $239^{2}$ \\
\hline Short-acting bronchodilator & $37(13.8 \%)$ & & $26(10.9 \%)$ & \\
\hline Long-acting \pm short-acting bronchodilator & $57(21.3 \%)$ & & $88(36.9 \%)$ & \\
\hline ICS + long-acting bronchodilator & $87(32.5 \%)$ & & $92(38.5 \%)$ & \\
\hline ICS \pm short-acting bronchodilator & $57(21.3 \%)$ & & $23(9.6 \%)$ & \\
\hline Other ICS combination & $15(5.6 \%)$ & & $6(2.5 \%)$ & \\
\hline Other & $15(5.6 \%)$ & & $4(1.6 \%)$ & \\
\hline Concomitant medication, $\mathrm{N}(\%)^{3}$ & & $167^{4}$ & & $258^{4}$ \\
\hline Long-acting anticholinergic \pm short-acting bronchodilator & $53(31.7 \%)$ & & $173(67.1 \%)$ & \\
\hline Short-acting bronchodilator & $81(48.5 \%)$ & & $71(27.5 \%)$ & \\
\hline Long-acting $\beta$-2 adrenergic agonist & $18(10.8 \%)$ & & $11(4.3 \%)$ & \\
\hline Other ICS & $15(9.0 \%)$ & & $3(1.2 \%)$ & \\
\hline
\end{tabular}

'During the 12 months prior to inclusion.

${ }^{2}$ Missing data for $84 \mathrm{GP}$ and 119 pulmonologist patients.

${ }^{3}$ At the time of FSC initiation.

${ }^{4}$ Missing data for $185 \mathrm{GP}$ and 100 pulmonologist patients.

COPD and dyspnea, and better QoL; see Additional file 2).

It could also be hypothesized that perceived QoL is a particularly important determinant of treatment decisions by GPs. Indeed, health-related QoL as measured by the CCQ was similar in pulmonologist and GP patients despite the latter patients having a lower dyspnea grade, less pronounced airflow obstruction and less frequent hospital visits. This illustrates that QoL measures, even when specifically designed for COPD patients, capture the impact of components other than those directly related to COPD. Interestingly, GP patients were younger and less likely to be retired than those treated by pulmonologists. Thus, it could be hypothesized that their perception of the disease's impact is enhanced by their activity requirements, although this possibility remains to be tested. It was also noted that although pulmonologist patients are likely to have more severe COPD, pulmonologists tend to be more restrictive in the use of antibiotics and corticosteroids in patients treated in the community, as recommended in the French COPD guidelines. In these guidelines, antibiotics are recommended only when sputum is purulent, and corticosteroids are to be prescribed only for patients with severe baseline airflow obstruction and/or lack of improvement following treatment with antibiotics, if required, and bronchodilators.

Another potential reason for discrepancy between the licensed and real-life COPD populations may lie with the possibility that exacerbations were underestimated in this study since they were only assessed from patient recall; interestingly, conformance with this criterion was particularly low among pulmonologists. A low level of overall conformity was maintained in a sensitivity analysis excluding this criterion. Difficulty evaluating prior exacerbations stems from multiple sources; not only is there an absence of consensus on the definition of COPD exacerbations [21-23], but in addition, patients tend to under-report exacerbations [24], even those that have clinical significance [25].

Differences in conformity were seen according to prior corticosteroid intake, with patients having prior ICS generally less likely to conform to prescription recommendations relative to ICS-naïve patients. This may have been influenced by the fact that prior ICS treatment may 
Table 3 Compliance of practice patterns with FSC marketing conditions for prescription according to prior ICS intake, irrespective of $\mathrm{FEV}_{1}$ availability

\begin{tabular}{|c|c|c|c|c|}
\hline & \multicolumn{2}{|c|}{ Patients with prior ICS } & \multicolumn{2}{|c|}{ ICS-naïve patients } \\
\hline & $\begin{array}{c}\text { GPs } \\
(n=159)\end{array}$ & $\begin{array}{l}\text { Pulmonologists } \\
(n=120)\end{array}$ & $\begin{array}{c}\text { GPs } \\
(n=193)\end{array}$ & $\begin{array}{l}\text { Pulmonologists } \\
(n=238)\end{array}$ \\
\hline \multicolumn{5}{|l|}{ Approved prescription condition respected, N (\%) } \\
\hline $\mathrm{FEV}_{1}<60 \%$ predicted $^{1}$ & $53(33.3 \%)$ & $76(63.3 \%)$ & $28(14.5 \%)$ & $144(60.5 \%)$ \\
\hline History of repeated exacerbations & $109(68.6 \%)$ & $51(42.5 \%)$ & $113(58.5 \%)$ & $55(23.1 \%)$ \\
\hline Continuous bronchodilator therapy & $101(63.5 \%)$ & $97(80.8 \%)$ & $57(29.5 \%)$ & $89(37.4 \%)$ \\
\hline All conditions respected (regulatory approval criteria) & $25(15.7 \%)$ & $31(25.8 \%)$ & $6(3.1 \%)$ & $16(6.7 \%)$ \\
\hline \multicolumn{5}{|l|}{ Details of conditions respected, N (\%) } \\
\hline None & $15(9.4 \%)$ & $6(5.0 \%)$ & $53(27.5 \%)$ & $47(19.7 \%)$ \\
\hline $\mathrm{FEV}_{1}$ only & $5(3.1 \%)$ & $5(4.2 \%)$ & $9(4.7 \%)$ & $69(29.0 \%)$ \\
\hline Repeated exacerbations only & $27(17.0 \%)$ & $2(1.7 \%)$ & $66(34.2 \%)$ & $13(5.5 \%)$ \\
\hline Continuous bronchodilator only & $18(11.3 \%)$ & $28(23.3 \%)$ & $13(6.7 \%)$ & $28(11.8 \%)$ \\
\hline $\mathrm{FEV}_{1}$ and repeated exacerbations only & $11(6.9 \%)$ & $10(8.3 \%)$ & $8(4.1 \%)$ & $20(8.4 \%)$ \\
\hline $\mathrm{FEV}_{1}$ and bronchodilators only & $12(7.5 \%)$ & $30(25.0 \%)$ & $5(2.6 \%)$ & $39(16.4 \%)$ \\
\hline Repeated exacerbations and bronchodilators only & $46(28.9 \%)$ & $8(6.7 \%)$ & $33(17.1 \%)$ & $6(2.5 \%)$ \\
\hline $\mathrm{FEV}_{1}$ and repeated exacerbations $+/-$ bronchodilators & $36(22.6 \%)$ & $41(34.2 \%)$ & $14(7.3 \%)$ & $36(15.1 \%)$ \\
\hline $\mathrm{FEV}_{1}$ or repeated exacerbations & $126(79.2 \%)$ & $86(71.7 \%)$ & $127(65.8 \%)$ & $163(68.5 \%)$ \\
\hline \multicolumn{5}{|l|}{$\mathrm{N}$ conditions respected, $\mathrm{N}(\%)$} \\
\hline At least one & $144(90.6 \%)$ & $114(95.0 \%)$ & $140(72.5 \%)$ & $191(80.3 \%)$ \\
\hline At least two & $94(59.1 \%)$ & $79(65.8 \%)$ & $52(26.9 \%)$ & $81(34.0 \%)$ \\
\hline
\end{tabular}

${ }^{1}$ Missing FEV 1 data were considered non-respect of condition.

have modified their clinical profile [26]. It may also be explained by the fact that this population was older, had more severe and longer duration COPD, with a higher incidence of oral corticosteroid and antibiotic intake.

Poor physician compliance with licensed conditions may also reflect a level of difficulty in applying recommendations and guidelines in the face of lack of clarity or simplicity, or in the context of individualized patient care. As reported by Corrado et al., recommendations can be considered inappropriate if other factors such as pulmonary hyperinflation, exercise capacity and tolerance, or comorbidities are not taken into account [27]. This may also explain the relatively high rates of incorrect dose prescription. Dialogue with physicians, along with improved awareness and education are needed in order to address these issues.

Analysis of populations and SPC conformance according to the GOLD 2011 classification reveals some differences compared to GOLD 2006 classification. Very severe airflow obstruction (GOLD grade 4) was reported in approximately one-quarter of the population while $40 \%$ belonged to the D GOLD 2011 category. In nearly a quarter of cases, GPs prescribed FSC to patients with GOLD 2006-defined mild COPD. This may be due to the fact that they (along with pulmonologists) tended to underestimate COPD severity relative to both 2006 and 2011 GOLD classifications (notably for most severe disease). Comparing the GOLD 2006 and 2011 classifications also shows that according to the latter, GPs were more likely than pulmonologists to see patients with more severe COPD ( $74 \%$ versus $55 \%$, respectively), which was not the case with the 2006 guidelines (32\% versus 38\%, respectively). Furthermore, according to the GOLD 2011 classification, more patients have more severe disease, suggesting a higher rate of conformity with the SPC licensing conditions, and also that the guidelines may be evolving to adapt to the real-life situation.

Another potential study limitation concerns the representativeness of participating physicians. The low rate of physicians selected randomly from the national population who agreed to participate in the study $(<10 \%)$ suggests a general reluctance to participate and consequently a potential selection bias. Nonetheless, participating physicians were broadly representative of national figures for their respective specialties in terms of age, gender and practice settings [28], although male physicians were overrepresented relative to national figures. It could be hypothesized that participating physicians were more likely to be interested in the field of COPD and prescribe treatments more adequately than less interested physicians. As a consequence, the already very high rate of nonconcordance between prescriptions and guidelines could 
be under-estimated. However, we have no means of testing this pessimistic hypothesis.

\section{Conclusions}

The COPD population prescribed with FSC by both GPs and pulmonologists conforms poorly with the licensed population with less than a quarter of ICS-treated patients and $7 \%$ of ICS-naive patients fulfilling all three marketing conditions. Prescribing clinicians need further education on the importance of following the SPC recommendations, including $\mathrm{FEV}_{1}$ evaluation, to ensure FSC is used only in COPD patients who are likely to benefit from it. Understanding the reasons behind clinicians' decisions to prescribe FSC to non-conforming patients may help to resolve this issue.

\section{Additional files}

\section{Additional file 1: Physician demographics and practice} characteristics.

Additional file 2: Comparison of patient characteristics between various groups.

Additional file 3: COPD therapeutic management.

Additional file 4: Compliance in patients with available $\mathrm{FEV}_{1}$ data.

\section{Abbreviations}

CAT: COPD Assessment Test; CCQ: Clinical COPD questionnaire; COPD: Chronic obstructive pulmonary disease; $\mathrm{FEV}_{1}$ : Forced expiratory volume in $1 \mathrm{sec}$; FSC: Fluticasone/salmeterol combination; GOLD: Global initiative for chronic obstructive lung disease; GP: General practitioner; ICS: Inhaled corticosteroids; LABA: Long-acting $\beta 2$ agonists; mMRC: Modified Medical Research Council; QoL: Quality of life; SD: Standard deviation; SPC: Summary of Product Characteristics.

\section{Competing interests}

Nicolas Roche has received over the past 5 years (i) fees for speaking, organising education, or consulting from Aerocrine, Almirall, Altana PharmaNycomed-Takeda, AstraZeneca, Boehringer Ingelheim, Chiesi, GlaxoSmithKline, MEDA, MSD-Chibret, Mundipharma, Novartis, Pfizer, Teva; (ii) research grants from Novartis, Nycomed, Boehringer Ingelheim and Pfizer.

Eric Van Ganse has received fees for: Consultancy from Danone, ALK-ABELLO, Chiesi; Expert testimony from UBS, IMS; Grants: IMS, CNAM, MSD, GSK; Travel/ accommodations related to a consultancy from Boehringer-Ingelheim. Philippe Serrier has received fees for speaking, consulting and attending conferences from Novartis, GSK, Pfizer, Boehringer Ingelheim, Astra Zeneca, Mundipharma, Vivisol, and Chiesi.

Bruno Housset has received fees from Aerocrine, Astra Zeneca, Boehringer Ingelheim, Chiesi, GlaxoSmithKline, Novartis, Nycomed, and Pfizer for performing continuing medical education talks and consulting work. Déborah Poirier, Nathalie Texier and Stéphane Schück were funded by GSK to perform study analyses.

Céline Pribil and Isabelle Boucot are employees of GSK.

\section{Authors' contributions}

All authors approved the original study protocol, data collection and analysis plans, and the study report, as well a revising the manuscript, and have approved the submitted version. In addition, NR participated in drafting the manuscript, and NT, DP, SS performed data management and statistical analyses.

\section{Acknowledgements}

We thank Virginie Rondeau (ISPED, INSERM, Bordeaux, France) for expert analysis of longitudinal data and Sarah MacKenzie (Medi.Axe, France) for medical writing services funded by GSK.

\section{Author details}

${ }^{1}$ Respiratory and Intensive Care Medicine, Cochin Hospital Group, AP-HP, University Paris Descartes, HIA du Val de Grâce 4e C, Paris, France. ²Department of Pharmacoepidemiology and Medico-Economic Modelling, GlaxoSmithKline, Marly Le Roi, France. ${ }^{3}$ Department of Pharmacoepidemiology, CHU-Lyon, Lyon, France. ${ }^{4}$ Private Medical Practice, Paris, France. ${ }^{5}$ Department of Pulmonology, CHI Creteil Hospital, Créteil, France. ${ }^{6}$ Kappa Santé, Paris, France. ${ }^{7}$ Respiratory and Immuno-Inflammation Department, GlaxoSmithKline, Marly Le Roi, France.

Received: 31 October 2013 Accepted: 24 March 2014

Published: 2 April 2014

\section{References}

1. Murray CJ, Lopez AD: Alternative projections of mortality and disability by cause 1990-2020: Global Burden of Disease Study. Lancet 1997, 349:1498-1504.

2. GOLD: Global Initiative for Chronic Obstructive Lung Disease. Global strategy for the diagnosis, management, and prevention of chronic obstructive pulmonary disease; 2014. Available from http://www.goldcopd.org/guidelines-globalstrategy-for-diagnosis-management.html. (Accessed April 2014).

3. Jenkins CR, Jones PW, Calverley PM, Celli B, Anderson JA, Ferguson GT, Yates JC, Willits LR, Vestbo J: Efficacy of salmeterol/fluticasone propionate by GOLD stage of chronic obstructive pulmonary disease: analysis from the randomised, placebo-controlled TORCH study. Respir Res 2009, 10:59. doi:10.1186/1465-9921-10-59.

4. Fitch K, Iwasaki K, Pyenson B, Plauschinat C, Zhang J: Variation in adherence with Global Initiative for Chronic Obstructive Lung Disease (GOLD) drug therapy guidelines: a retrospective actuarial claims data analysis. Curr Med Res Opin 2011, 27:1425-1429.

5. Incalzi RA, Corsonello A, Pedone C, Masotti G, Bellia V, Grassi V, Rengo F: From Global Initiative for Chronic Obstructive Lung Disease (GOLD) guidelines to current clinical practice: an overview of the pharmacological therapy of stable chronic obstructive pulmonary disorder. Drugs Aging 2006, 23:411-420.

6. Roche N, Lepage T, Bourcereau J, Terrioux P: Guidelines versus clinical practice in the treatment of chronic obstructive pulmonary disease. Eur Respir J 2001, 18:903-908.

7. Han MK, Kim MG, Mardon R, Renner P, Sullivan S, Diette GB, Martinez FJ: Spirometry utilization for COPD: how do we measure up? Chest 2007, 132:403-409.

8. Olsen S, Jarbøl DE, Kofoed M, Abildskov K, Pedersen ML: Prevalence and management of patients using medication targeting obstructive lung disease: a cross-sectional study in primary healthcare in Greenland. Int $J$ Circumpolar Health 2013, 72. doi:10.3402/ijch.v72i0.20108.

9. Chavez PC, Shokar NK: Diagnosis and management of chronic obstructive pulmonary disease (COPD) in a primary care clinic. COPD 2009, 6:446-451.

10. Arne M, Lisspers K, Ställberg B, Boman G, Hedenström H, Janson C, Emtner $\mathrm{M}$ : How often is diagnosis of COPD confirmed with spirometry? Respir Med 2010, 104:550-556.

11. Koefoed MM, de Pont Christensen R, Søndergaard J, Jarbøl DE: Lack of spirometry use in Danish patients initiating medication targeting obstructive lung disease. Respir Med 2012, 106:1743-1748.

12. Borg G: Perceived exertion as an indicator of somatic stress. Scand J Rehabil Med 1970, 2:92-98.

13. Van der Molen T, Willemse BW, Schokker S, ten Hacken NH, Postma DS, Juniper EF: Development, validity and responsiveness of the Clinical COPD Questionnaire. Health Qual Life Outcomes 2003, 1:13.

14. GOLD: Global Initiative for Chronic Obstructive Lung Disease. Global strategy for the diagnosis, management, and prevention of chronic obstructive pulmonary disease; 2006. http://www.goldcopd.org/Guidelines/guidelinesglobal-strategy-for-diagnosis-management-2006.html. (Accessed April 2014).

15. GOLD: Global Initiative for Chronic Obstructive Lung Disease. Global strategy for the diagnosis, management, and prevention of chronic obstructive pulmonary disease; 2010. http://www.goldcopd.org/Guidelines/guideline2010-gold-report.html. (Accessed April 2014).

16. Calverley P, Pauwels R, Vestbo J, Jones P, Pride N, Gulsvik A, Anderson J, Maden C: TRial of Inhaled STeroids ANd long-acting beta2 agonists study group: Combined salmeterol and fluticasone in the treatment of chronic obstructive pulmonary disease: a randomised controlled trial. Lancet 2003, 361:449-456. 
17. Mahler DA, Wire P, Horstman D, Chang C-N, Yates J, Fischer T, Shah T: Effectiveness of fluticasone propionate and salmeterol combination delivered via the Diskus device in the treatment of chronic obstructive pulmonary disease. Am J Respir Crit Care Med 2002, 166:1084-1091.

18. Hanania NA, Darken P, Horstman D, Reisner C, Lee B, Davis S, Shah T: The efficacy and safety of fluticasone propionate $(250 \mathrm{microg}) / \mathrm{salmeterol}$ (50 microg) combined in the Diskus inhaler for the treatment of COPD. Chest 2003, 124:834-843.

19. Gershon AS, Victor JC, Guan J, Aaron SD, To T: Pulmonary function testing in the diagnosis of asthma: a population study. Chest 2012, 141:1190-1196.

20. Buffels J, Degryse J, Liistro G: Diagnostic certainty, co-morbidity and medication in a primary care population with presumed airway obstruction: the DIDASCO2 study. Prim Care Respir J 2009, 18:34-40.

21. Rodriguez-Roisin R: Toward a consensus definition for COPD exacerbations. Chest 2000, 117(5 Suppl 2):398S-401S

22. Burge S, Wedzicha JA: COPD exacerbations: definitions and classifications. Eur Respir J Suppl 2003, 41:46s-53s.

23. Pauwels R, Calverley P, Buist AS, Rennard S, Fukuchi Y, Stahl E, Löfdahl CG: COPD exacerbations: the importance of a standard definition. Respir Med 2004, 98:99-107.

24. Seemungal TA, Donaldson GC, Paul EA, Bestall JC, Jeffries DJ, Wedzicha JA: Effect of exacerbation on quality of life in patients with chronic obstructive pulmonary disease. Am J Respir Crit Care Med 1998, 157(5 Pt 1):1418-1422.

25. Langsetmo L, Platt RW, Ernst P, Bourbeau J: Underreporting exacerbation of chronic obstructive pulmonary disease in a longitudinal cohort. Am J Respir Crit Care Med 2008, 177:396-401.

26. Burge PS, Calverley PM, Jones PW, Spencer S, Anderson JA, Maslen TK: Randomised, double blind, placebo controlled study of fluticasone propionate in patients with moderate to severe chronic obstructive pulmonary disease: the ISOLDE trial. BMJ 2000, 320:1297-1303.

27. Corrado A, Rossi A: How far is real life from COPD therapy guidelines? An Italian observational study. Respir Med 2012, 106:989-997.

28. DREES (French Ministry of Health Directorate for Research, Evaluation and Statistics): [Physicians: Estimations on January 1, 2008. Statistical Series, No. 127, October 2008] in French; 2013. http://www.drees.sante.gouv.fr/IMG/pdf/ seriestat127.pdf. (Accessed September 2013).

doi:10.1186/1471-2466-14-56

Cite this article as: Roche et al:: Real-life use of fluticasone propionate/ salmeterol in patients with chronic obstructive pulmonary disease: a French observational study. BMC Pulmonary Medicine 2014 14:56.

\section{Submit your next manuscript to BioMed Central and take full advantage of:}

- Convenient online submission

- Thorough peer review

- No space constraints or color figure charges

- Immediate publication on acceptance

- Inclusion in PubMed, CAS, Scopus and Google Scholar

- Research which is freely available for redistribution

Submit your manuscript at www.biomedcentral.com/submit
C Biomed Central 